\title{
Can use of an administrative database improve accuracy of hospital-reported readmission rates?
}

\author{
James R. Edgerton, MD, ${ }^{\mathrm{a}, \mathrm{b}}$ Morley A. Herbert, PhD, ${ }^{\mathrm{a}, \mathrm{c}}$ Baron L. Hamman, MD, ${ }^{\mathrm{a}, \mathrm{d}}$ and \\ W. Steves Ring, $\mathrm{MD}^{\mathrm{a}, \mathrm{e}}$
}

\section{ABSTRACT}

Objectives: Readmission rates after cardiac surgery are being used as a quality indicator; they are also being collected by Medicare and are tied to reimbursement. Accurate knowledge of readmission rates may be difficult to achieve because patients may be readmitted to different hospitals. In our area, 81 hospitals share administrative claims data; 28 of these hospitals (from 5 different hospital systems) do cardiac surgery and share Society of Thoracic Surgeons (STS) clinical data. We used these 2 sources to compare the readmissions data for accuracy.

Methods: A total of 45,539 STS records from January 2008 to December 2016 were matched with the hospital billing data records. Using the index visit as the start date, the billing records were queried for any subsequent in-patient visits for that patient. The billing records included date of readmission and hospital of readmission data and were compared with the data captured in the STS record.

Results: We found 1153 (2.5\%) patients who had STS records that were marked "No" or "missing," but there were billing records that showed a readmission. The reported STS readmission rate of $4796(10.5 \%)$ underreported the readmission rate by 2.5 actual percentage points. The true rate should have been $13.0 \%$. Actual readmission rate was $23.8 \%$ higher than reported by the clinical database. Approximately $36 \%$ of readmissions were to a hospital that was a part of a different hospital system.

Conclusions: It is important to know accurate readmission rates for quality improvement processes and institutional financial planning. Matching patient records to an administrative database showed that the clinical database may fail to capture many readmissions. Combining data with an administrative database can enhance accuracy of reporting. (J Thorac Cardiovasc Surg 2018;155:2043-7)

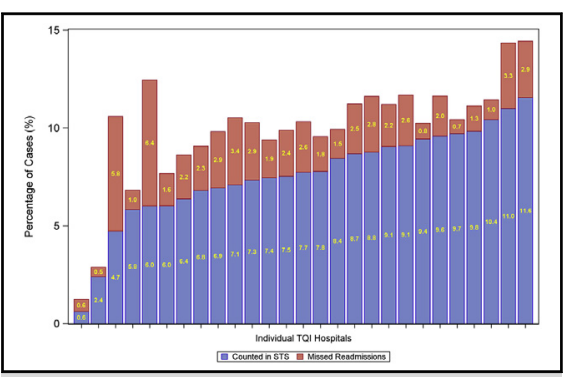

Increased readmission rates using data from administrative database.

\section{Central Message}

It is important to know accurate readmission rates for quality improvement processes and institutional financial planning. Matching patient records to an administrative database can enhance accuracy of reporting.

\section{Perspective}

An accurate assessment of readmission rate after cardiac surgery is critical, as it is a quality indicator and is important for financial planning. The Society of Thoracic Surgeons clinical database can fail to capture all readmissions. In a large, regional cooperative, we demonstrate that the use of an administrative database paired with the clinical database can improve accuracy of reporting. It is important to know accurate readmission rates for quality improvement processes and institutional financial planning. Matching patient records to an administrative database can enhance accuracy of reporting.

See Editorial Commentary page 2048

\footnotetext{
From the ${ }^{\mathrm{a}}$ Texas Quality Initiative, Irving, Tex; ${ }^{\mathrm{b}}$ The Heart Hospital Baylor Plano, Plano, Tex; ${ }^{\mathrm{c} D e p a r t m e n t}$ of Clinical Research, Medical City, Dallas, Tex; ${ }^{\mathrm{d} D e p a r t-}$ ment of Cardiovascular Surgery, Texas Health Resources, Arlington, Tex; ${ }^{\mathrm{e}}$ Department of Cardio-Thoracic Surgery, University of Texas Southwestern Medical Center, Dallas, Tex.

Read at the 97th Annual Meeting of The American Association for Thoracic Surgery, Boston, Massachusetts, April 29-May 3, 2017.

Received for publication April 28, 2017; revisions received Oct 5, 2017; accepted for publication Nov 19, 2017; available ahead of print Jan 10, 2018.

Address for reprints: James R. Edgerton, MD, The Heart Hospital Baylor Plano, 4716 Alliance Blvd, Pavilion II, Ste 300, Plano, TX 75093 (E-mail: JamesEdgertonMD@Gmail.com).

0022-5223/ $\$ 36.00$

Copyright (c) 2017 by The American Association for Thoracic Surgery

https://doi.org/10.1016/j.jtcvs.2017.11.071
}

Hospital readmission after heart surgery has become a quality indicator. In June 2007, the Medicare Payment Advisory Commission prepared the "Report to the Congress: Promoting Greater Efficiency in Medicine," in which they state

Scanning this $\mathrm{QR}$ code will take you to the article title page. 


\section{Abbreviations and Acronyms \\ ACSD = Adult Cardiac Surgery Database \\ $\mathrm{CABG}=$ coronary artery bypass grafting \\ CMS $=$ Center for Medicare and Medicaid Services \\ DFWHCF $=$ Dallas-Fort Worth Hospital Council Foundation \\ REMPI $=$ Regional Enterprise Master Patient Index \\ STS $=$ Society of Thoracic Surgeons \\ TQI $=$ Texas Quality Initiative}

that "hospital readmissions are sometimes indicators of poor care or missed opportunities to better coordinate care." They go on to state that "failure to adequately attend to care transition at discharge from the hospital results in additional Medicare spending; $17.6 \%$ of admissions result in readmissions within 30 days of discharge accounting for $\$ 15$ billion in spending. Not all of these readmissions are avoidable, but some are." ${ }^{1}$ In a 2010 study of 10 US and Canadian hospital's ${ }^{2}$ readmission rates ranged from $14.9 \%$ for coronary artery bypass grafting (CABG) to $25 \%$ for CABG and valve (CABG/valve). The most common causes were arrhythmia, infection, and volume overload. The Center for Medicare and Medicaid Services (CMS) had a report prepared by Yale New Haven Health Services Corporation and the Center for Outcomes Research and Evaluation (revised 2014). It indicated that in the Medicare population, readmissions after cardiac surgery were $16.8 \%$, and 30 -day mortality for readmitted patients was $2.8 \%$, threefold higher than patients not readmitted. They identified the reasons for readmission as: complications of therapy, inadequate treatment, inadequate care coordination at discharge, and unexpected worsening of disease after discharge.

In the new era of pay for performance, readmission rate has financial implications. In a follow-up to the 2007 Medicare Payment Advisory Commission report, in 2008 the Medicare Payment Advisory Commission prepared a "Report to the Congress: Reforming the Delivery System" in which they state, "To encourage providers to collaborate and better coordinate, the Congress should direct the Secretary to reduce payments to hospitals with relatively high readmission rates." ${ }^{3}$ In Section 3205 of the Affordable Care Act of 2010, named the "Hospital Readmissions Reduction Program (HRRP)," the US Congress authorized CMS to reduce payments to hospitals with excess readmissions starting in $2012 .{ }^{4}$ The legislation stated that hospital reimbursement for all its readmissions would be reduced if readmission rate for heart failure, acute myocardial infarction, and pneumonia exceeded predicted rates. The maximum reduction was $1 \%$ in 2013 , increasing to $3 \%$ in 2015 . In 2017 , CABG was added to the diagnoses for which readmission rates are monitored. Furthermore, the coming CMS Episode Payment Model and Cardiac Rehab Incentive Program will reimburse for 90 days of care. This bundled payment care incentive will initially be only for isolated CABG, will be for 90 days of care, and will include Medicare Parts A and B, skilled nursing facility stay, home health care, and all care for a related readmission. The financial implications will likely be most pronounced for institutions with an elevated CABG readmission rate. This program was recently put on hold but signals CMS intent and possible future direction.

Thus, rate of readmission after cardiac surgery has important quality and financial implications. To improve quality and to plan for a changing reimbursement model, hospitals need to have accurate information on their readmission rates. Shahian and colleagues ${ }^{5}$ have previously shown a discrepancy between readmission rates clinically recorded and those captured by CMS. However, this study was confined to the Medicare population, and limited to isolated CABG surgery. We sought to compare readmission rates recorded in the Society of Thoracic Surgeons (STS) Adult Cardiac Surgery Database (ACSD) to an administrative charge-based database to evaluate the accuracy of reported regional readmission rates for all patients undergoing cardiac surgery. Our hypothesis was that combining the two sources of data would improve the accuracy of the reported readmission data.

\section{METHODS}

The Texas Quality Initiative (TQI) is a regional quality improvement cooperative involving 28 hospitals in the Dallas-Fort Worth Metroplex with cardiac surgery programs. All the TQI hospitals participate in the STS ACSD, and twice a year submit a copy of their STS ACSD data to a central repository maintained by the Dallas-Fort Worth Hospital Council Foundation (DFWHCF). The DFWHCF is a 501(c)(3) not-for-profit charitable organization dedicated to improving the region's patient safety and quality of care.

The foundation also maintains a database of all administrative claims data submitted using an 837 Electronic Data Interchange format on a monthly basis to the DFWHCF Information and Quality Services Center, which oversees the data warehouse. Eighty-one hospitals participate in the administrative database, which also includes all the TQI participants. The TQI data consist of STS clinical data, whereas the administrative (claims) database covers financial billing data records. A Regional Enterprise Master Patient Index (REMPI) is then generated from the administrative claims database. Using selected fields (date of surgery, hospital, surgeon, patient age, length of stay, admit date, discharge date) from the STS data, we can match the TQI records (deidentified with regard to names and Social Security numbers) to the claims data records. All matching information returned for research analysis is also deidentified regarding patient name and Social Security number.

For STS surgery records before July 1, 2014, readmission was calculated for a 30-day window after surgery. After July 1, 2014 (ie, data version 2.81 , the definition was changed to include the period of 30 days after discharge by CMS, with STS changing their definition for consistency. In both time frames, all-cause readmission was counted.

The protocol was reviewed by the North Texas Institutional Review Board at Medical City Dallas and classified as exempt status. A file of records from the TQI database was then matched to corresponding records 
from the administrative database and queried for any record of a hospital inpatient encounter within a 30-day window after the discharge date. The returned data file was then merged back into our TQI master file for comparison of the STS readmission data to that found in the administrative data. Because readmission is "all cause," we accepted any readmission. The returned dataset not only showed the date of the encounter but also the hospital where it occurred. Statistical analyses were performed using SAS version 9.4 (SAS Institute, Cary, NC).

\section{RESULTS}

A total of 45,539 unique records from TQI patients discharged alive between January 1, 2008, and December 31, 2016, were matched with corresponding REMPI records from the 81 participating hospitals. The administrative data query looked for the date of any hospital inpatient encounter up to 1 year from the date of surgery. These results were then corrected to account for readmissions within 30 days from the surgery date for data before July 1, 2014 (STS versions $2.61,2.73$ ) and within 30 days of the discharge date for later data collected using STS version 2.81. Figure 1 shows rate of readmission for the 28 hospitals participating in the study as reported in the clinical database and additional readmissions found in the administrative database.

Table 1 is a breakdown of the data recorded in the STS clinical database and the administrative (financial) database. Row 1 shows the number of patients with no readmission indicated in the STS data and confirmed by finding no subsequent admission in the matched patient's claims data. Row 2 is the number of readmissions recorded in the STS clinical database for the system with either a corresponding readmission record in the claims database, or in some cases no record (cases where the readmission is to a facility outside the DFWHC area and not providing claims data). Row 3 is the number of records indicating no readmission (or missing) in the STS data, but the administrative match found a readmission for the patient; this represents an increase of 2.5 absolute percentage points in the readmission rate from an indicated $10.5 \%$ (column 2 ) to an actual $13.0 \%$ - a $23.8 \%$ increase over the reported rate.

One possible reason for missed readmissions is that patients were readmitted to a different hospital than the index admission, especially if the hospital is part of a different hospital system. Some hospitals keep common patient record databases within their system; these can be used to find patients readmitted within the system but at a different hospital. Tracking readmissions into other systems requires contact with the patient, their family, or a physician with knowledge of the event. A maximum of $3.4 \%$ of the records had a readmission recorded in the STS but not in the REMPI. The likely explanation is that these patients were readmitted to a hospital that is a non-DFWHC institution (out of area).

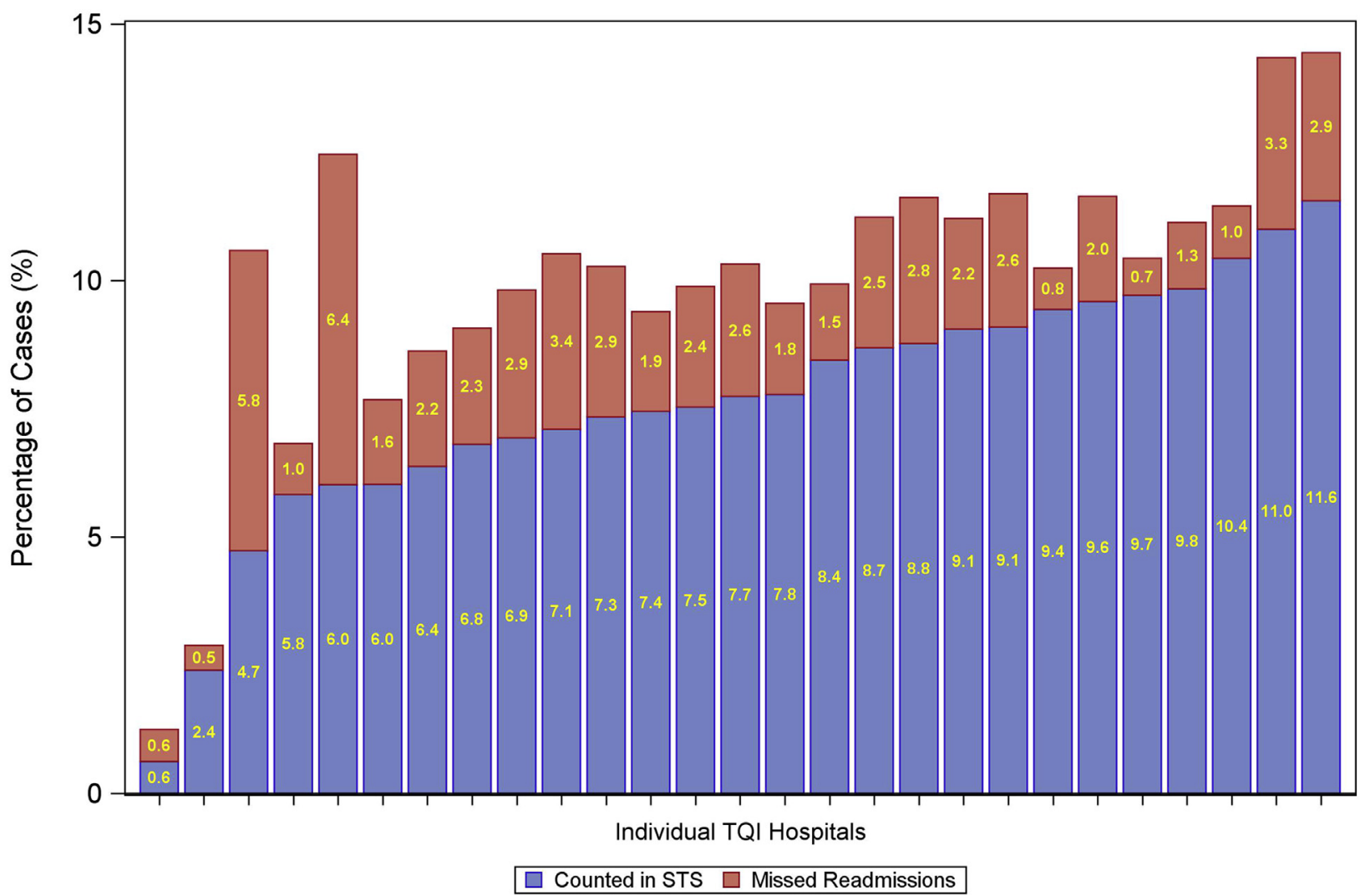

FIGURE 1. The reported rate of readmission for the 28 hospitals participating in the study. The blue bars are taken from their Society of Thoracic Surgeons (STS) reported data, and the red sections are the readmissions found by matching with the administrative data. 
TABLE 1. Results of matching the Society of Thoracic Surgeons clinical database with administrative claims data

\begin{tabular}{|c|c|c|c|c|c|c|}
\hline & System A (\%) & System B (\%) & System C (\%) & System D (\%) & System E (\%) & Totals \\
\hline $\begin{array}{l}\text { Institutional = No } \\
\text { Administrative }=\text { No }\end{array}$ & $17,469(87.5)$ & 9432 (85.6) & $1273(86.7)$ & $7271(85.1)$ & $3576(78.9)$ & 39,021 (85.7) \\
\hline $\begin{array}{l}\text { Institutional }=\text { Yes } \\
\text { Administrative }=\text { Yes or No }\end{array}$ & $1526(7.7)$ & $1338(12.1)$ & $162(11.0)$ & 885 (10.4) & $885(19.5)$ & $4796(10.5)$ \\
\hline $\begin{array}{l}\text { Institutional }=\text { No or Missing } \\
\text { Administrative }=\text { Yes }\end{array}$ & $549(2.7)$ & 208 (1.9) & $18(1.2)$ & $312(3.7)$ & $66(1.5)$ & $1153(2.5)$ \\
\hline $\begin{array}{l}\text { Institutional }=\text { Missing } \\
\text { Administrative }=\text { No }\end{array}$ & $428(2.1)$ & $46(0.4)$ & $16(1.1)$ & $75(0.9)$ & $4(0.1)$ & $569(1.2)$ \\
\hline Total & 19,972 & 11,024 & 1469 & 8543 & 4531 & 45,539 \\
\hline
\end{tabular}

Combining data for patients where the STS Readmission field was marked as Yes or Missing, or where the field was marked $N o$ but the administrative data showed a readmission, Table 2 shows where the readmissions occurred for each chain.

Admissions to different systems varied from $10 \%$ to $33.5 \%$, making accurate record keeping a challenge.

\section{DISCUSSION}

Knowledge of accurate readmission rates after cardiac surgery is important for quality assessment and financial planning. Risk models developed to predict readmission rates after CABG have been inherently unreliable. ${ }^{5-9}$ With predictive models not being great discriminators, accurate tracking of readmission rate becomes critical for process improvement. We have shown that the use of an administrative database can enhance the accuracy of a clinical database for readmission after cardiac surgery; this has been demonstrated previously in the Medicare population. Shahian et al. ${ }^{5}$ looked at the readmission rate after isolated CABG between 2008 and 2010 and compared this to the rate obtained from Medicare claims data. The readmission rate from the STS database was 10\% compared with $16.8 \%$ obtained from the Medicare data. Helping to explain this difference may be the fact that $50 \%$ of readmissions were to a different hospital than where the index procedure was performed.

To place our work in the framework of the modern literature, we can look to a recent study by Iribarne and colleagues $^{2}$ that examined all-cause readmission within 65 days after all cardiac surgeries in 5069 patients

TABLE 2. Readmission distribution

\begin{tabular}{lcr}
\hline Hospital system & $\begin{array}{c}\text { Same hospital } \\
\text { chain }(\%)\end{array}$ & $\begin{array}{c}\text { Not to same } \\
\text { chain }(\%)\end{array}$ \\
\hline A & $1198(70.3)$ & $506(29.7)$ \\
B & $910(84.0)$ & $173(16.0)$ \\
C & $117(90.0)$ & $13(10.0)$ \\
D & $657(71.0)$ & $268(29.0)$ \\
E & $348(66.5)$ & $175(33.5)$ \\
\hline
\end{tabular}

discharged from 10 medical centers between February and September 2010. ${ }^{2}$ The 30-day readmission rate was $13.2 \%$ (similar to our $13.0 \%$ ), and 65 -day readmission rate was $16.5 \%$. Of these patients, $80.6 \%$ were readmitted within 30 days. Overall readmission rate per procedure type was $14.9 \%$ for isolated CABG, $18.3 \%$ for isolated valve, and $25 \%$ for CABG plus valve. These 65 -day rates were higher than the current national 30-day rates, which were higher than our STS reported rate of $10.5 \%$ but closer to the rates we observed after correction with the administrative database.

The practical implication for hospitals that participate within a regional quality cooperative is clear. Obtaining administrative data for others may be more difficult. However, as hospital systems are coalescing into larger networks, and as large accountable care organizations are formed, the opportunity to match clinical data with large, financial charge-based administrative databases presents itself. Although administrative databases have frequently been maligned as misrepresenting clinical data, ${ }^{10,11}$ we have shown that these databases can be complimentary and even enhance the accuracy of a clinical database. ${ }^{12}$

\section{Limitations}

This study is limited by the regional nature of the administrative database. If a patient underwent an operation in a hospital participating in the administrative database, but was readmitted to a hospital outside the geographic boundaries of the administrative database, that readmission would not be captured. The result would be an even higher rate of missed readmissions.

In our study, the clinical database to administrative database match was greater than $95 \%$. Thus, some patients may be missed in this process because the match to the administrative data was not $100 \%$. Any error thus introduced would again underestimate the number of readmissions missed by the clinical database.

\section{CONCLUSIONS}

Readmission rate after cardiac surgery is underrepresented by the STS clinical database. The use of an 
administrative database can enhance the accuracy of reporting readmissions and potentially provide data for readmissions occurring up to 90 days after discharge, in accordance with new payment models. These data have important implications for both process improvement and financial planning.

\section{Conflict of Interest Statement}

Authors have nothing to disclose with regard to commercial support.

\section{References}

1. Medicare Payment Advisory Commission. Report to the Congress: Promoting Greater Efficiency in Medicare. Washington, DC: Medicare Payment Advisory Commission; 2007.

2. Iribarne A, Chang H, Alexander JH, Gillinov AM, Moquete E, Puskas JD, et al. Readmissions after cardiac surgery: experience of the National Institutes of Health/Canadian Institutes of Health Research Cardiothoracic Surgical Trials Network. Ann Thorac Surg. 2014;98:1274-80.

3. Medicare Payment Advisory Commission. Report to the Congress: Reforming the Delivery System. Washington, DC: Medicare Payment Advisory Commission; 2008.

4. Patient Protection and Affordable Care Act, H.R. 3590, Pub L No. 111-148 (2010).
5. Shahian DM, He X, O'Brien SM, Grover FL, Jacobs JP, Edwards FH, et al Development of a clinical registry based 30-day readmission measure for coronary artery bypass grafting. Circulation. 2014;130:399-409.

6. Hannan EL, Zhong Y, Lahey SJ, Culliford AT, Gold JP, Smith CR, et al. 30-day readmissions after coronary artery bypass graft surgery in New York State. JACC Cardiovasc Interv. 2011:4:569-76.

7. Lancey R, Kurlansky P, Argenziano M, Coady M, Dunton R, Greelish J, et al. Uniform standards do not apply to readmission following coronary artery bypass surgery: a multi-institutional study. J Thorac Cardiovasc Surg. 2015;149:850-7.

8. Shih T, Dimick JB. Reliability of readmission rates as a hospital quality measure in cardiac surgery. Ann Thorac Surg. 2014;97:1214-9.

9. Kansagara D, Englander H, Salanitro A, Kagen D, Theobald C, Freeman M, et al. Risk prediction models for hospital readmission. A systematic review. JAMA 2011;306:1688-98.

10. Jacobs JP, Shahian DM, He X, O'Brien SM, Badhwar V, Cleveland JC Jr, et al. Penetration, completeness, and representativeness of the Society of Thoracic Surgeons Adult Cardiac Surgery Database. Ann Thorac Surg. 2016;101:33-41.

11. Mack MJ, Herbert M, Prince S, Dewey TM, Magee MJ, Edgerton JR. Does reporting of coronary artery bypass grafting from administrative databases accurately reflect actual clinical outcomes? J Thorac Cardiovasc Surg. 2005;129: 1309-17.

12. Ring WS, Edgerton JR, Herbert MA, Prince SL, Knoff C, Jenkins KM, et al Impact of accurate 30-day status on operative mortality: wanted dead or alive, not unknown. Ann Thorac Surg. 2017;104:1987-93.

Key Words: readmission after cardiac surgery, clinical database, administrative database, readmission, database, hospital reported, accuracy of readmission

Readers who found these articles interesting may also like to read the following papers found in recent and future issues of our sister publications, Seminars in Thoracic and Cardiovascular Surgery and Operative Techniques in Thoracic and Cardiovascular Surgery!

\section{Adult: Perioperative Management}

ORIGINAL SUBMISSION: Early Outcomes with Rapid-Deployment Versus Stented Biological Valves: a Propensity-Match Analysis. Anthony Nguyen. Semin Thoracic Surg 2017: In press.

Editorial Commentary: Rapid-Deployment Aortic Valve Replacement: Clear Benefits Without a Clear Target Patient Population. Craig M. Jarrett. Semin Thoracic Surg 2017: In press.

ORIGINAL SUBMISSION: Randomized Trial of Carnitine for the Prevention of Perioperative Atrial Fibrillation. Farzaneh Dastan. Semin Thoracic Surg 2017: In press.

Editorial Commentary: Preventing Postoperative Atrial Fibrillation: is There One Best Option? Vincent R. Conti. Semin Thoracic Surg 2017: In press.

ORIGINAL SUBMISSION: Carbon Dioxide Insufflation during Cardiac Surgery. Meta-Analysis of Randomized Controlled Trials. Umberto Benedetto. Semin Thoracic Surg 2017: 301-310. 